Check for updates

Cite this: RSC Adv., 2017, 7, 33714

Received 10th May 2017

Accepted 26th June 2017

DOI: $10.1039 / \mathrm{c} 7 \mathrm{ra05298g}$

rsc.li/rsc-advances

\section{Carboxylic acids to butyl esters over dealuminated-realuminated beta zeolites for removing organic acids from bio-oils $\uparrow$}

\author{
Jianhua Li, $\$^{a}$ Haiyan Liu, $\hbar^{* a}$ Tingting An, ${ }^{a}$ Yuanyuan Yue ${ }^{b}$ and Xiaojun Bao (DD *b
}

This article describes a novel method to dealuminate and realuminate $\mathrm{H}$-beta zeolites as catalysts for removing organic acids from bio-oils via their esterification reactions with alcohols. Modified $\mathrm{H}$-beta zeolites were prepared by leaching with solutions of oxalic acid, DL-malic acid, and DL-tartaric acid that have different numbers of hydroxyl groups. The results showed that, while all three organic acids can dealuminate the parent $\mathrm{H}$-beta zeolite, with $\mathrm{Al}(\mathrm{VI})_{a}$ atoms and $\mathrm{Al}(\mathrm{IV})_{\mathrm{c}}$ ones being preferentially removed, they show quite different realumination abilities, with tartaric acid with two hydroxyl groups having the highest realumination ability. The concomitance of dealumination and realumination and their dependence on the hydroxyl group numbers of the organic acids provide the possibility of finely tuning the Al and acidity distributions of the resulting zeolites. Among the three acid treated $\mathrm{H}$-beta zeolites, the one obtained from malic acid leaching exhibited the best performance in catalyzing the esterification reaction between acetic acid and sec-butyl alcohol, attributed to its suitable quantity and density of medium and strong Brönsted acid sites and enhanced aluminum gradient. The catalytic results obtained in a fixed-bed microreactor revealed that the malic acid leached $\mathrm{H}$-beta exhibited dramatically enhanced catalytic performance compared to the commercial ion-exchange resin Amberlyst ${ }^{\circledR} 15$, demonstrating great potential for industrial application.

\section{Introduction}

Due to the fast depletion of fossil fuel reserves and the increasing awareness of the environmental impacts of fossil fuel combustion, renewable energy is now becoming key in moving the world economy towards a more sustainable future. ${ }^{1}$ In this respect, biomass is presently the only sustainable source of organic carbon, ${ }^{2}$ which necessitates the development of various processes to convert biomass to bio-oils as alternative fuels. ${ }^{3}$ Production of liquid bio-oils from biomass through thermal processes under fast pyrolysis conditions has great potential since the resulting bio-oils can be more conveniently fitted into the existing transportation fuel facilities than many other biofuels. However, a substantial amount of organic acids existing in thermal-pyrolysis bio-oils can lead to serious corrosion of process devices and lower storage stability. Therefore, it is necessary to decrease the content of organic acids in thermal pyrolysis bio-oils. Among various routes available, esterification

\footnotetext{
${ }^{a}$ State Key Laboratory of Heavy Oil Processing, China University of Petroleum, Beijing 102249, P. R. China. E-mail: baoxj@fzu.edu.cn; Fax: +8659122865220

${ }^{b}$ National Engineering Research Center of Chemical Fertilizer, College of Chemical Engineering, Fuzhou University, Fuzhou 350116, P. R. China

$\dagger$ Electronic supplementary information (ESI) available: Characterization methods and data. See DOI: 10.1039/c7ra05298g

\$ These authors contributed equally to this work.
}

reactions between acids and alcohols are considered to be promising. ${ }^{4}$ Esterification reactions are usually catalyzed by acidic catalysts, so development of high-performance acidic catalysts becomes key for the efficient conversion of acids in bio-oils.

Nowadays liquid mineral acids are the most heavily used catalysts for esterification reactions, but they suffer from several drawbacks such as serious corrosion to process devices, unavoidable formation of unwanted by-products, and difficult separation from the reaction system. To overcome the above drawbacks, various solid acid catalysts such as ion-exchange resins, ${ }^{\mathbf{5}, \mathbf{6}}$ heteropoly acids, ${ }^{7}$ zeolites $^{8}{ }^{8}$ fibres ${ }^{9}$ and solid superacids like sulphated zirconia $^{\mathbf{1 0}}$ and niobium acid $^{\mathbf{1 1}}$ have been extensively explored. Particularly, zeolite-based catalysts are now receiving increasing attention because of their high hydrothermal stability which can endow catalysts with longer life as compared with ion-exchange resins and their tunable acidity which can avoid the occurrence of side reactions as encountered for heteropoly acids and solid superacids. ${ }^{\mathbf{1 2}}$

It has been reported that, compared with ultra-stable zeolite Y (USY) with faujasite structure and zeolites with MFI structure, zeolite beta with BEA structure exhibits much better performance for esterification reactions. ${ }^{\mathbf{1 3}, \mathbf{1 4}}$ However, excessive strong acid sites and improper $\mathrm{Al}$ and acidity distributions in $\mathrm{H}$-form beta (H-beta) zeolites lead to poorer esterification selectivity and product yield. ${ }^{\mathbf{1 5 , 1 6}}$ Therefore, it is necessary to develop 
a novel method to finely tune the acidity of H-beta zeolites. It has been found that dealumination of beta zeolites by steaming, ${ }^{17}$ leaching with mineral acids such as $\mathrm{HCl},{ }^{18}$ and treatments with chemicals such as ammonium hexafluorosilicate, ${ }^{19}$ and organic acids ${ }^{\mathbf{2 0 , 2 1}}$ are effective for this purpose. Among these approaches, acid leaching is considered to be the most feasible route from the point of view of environmental protection and industrial application, but the negative effects of dealumination by acid leaching are structural changes in zeolite crystals and uncontrollable loss of framework aluminum atoms that decreases active sites. Therefore, it is desirable to reinsert aluminum atoms into the framework of the partially dealuminated framework of zeolite beta. Several routes have been proposed for the post-synthetic incorporation of aluminum into zeolites. The treatment with $\mathrm{AlCl}_{3}$ or $\mathrm{AlBr}_{3}$ vapor at higher temperature was found to be able to incorporate aluminum atoms into the framework of high-silica zeolite ZSM-5 and thus adjust its acidity and activity. ${ }^{22}$ It was also reported that extraframework $\mathrm{Al}$ species produced in hydrothermal treatment could be subsequently reinserted into the frameworks of $\mathrm{Y}^{23}$ ZSM-5 ${ }^{24}$ and beta $^{25}$ by treatments with an aqueous alkaline solution at elevated temperature. In addition, Omegna et al. ${ }^{26}$ reported that zeolite beta could be dealuminated by treatment with hydrochloric acid and realuminated by treating the dealuminated zeolite beta with aluminum isopropoxide. Fan et al. ${ }^{27}$ observed the realumination effect of citric acid on HZSM-5 zeolites dealuminated by steaming, and found that the steaming treatment prior to the citric acid leaching was the precondition of realuminating HZSM-5 zeolites. Xie et $a l^{28}$ also reported the realumination effect of single citric acid treatment on beta zeolite. While the aforementioned researches demonstrated the feasibility of realuminating dealuminated zeolites, it seems that there is no report on how to finely control the realumination process of beta zeolites by acid treatment, to which the present investigation is addressed.

Herein we present a thorough investigation on the modification of H-beta zeolite using the solutions of three organic acids (oxalic acid, DL-malic acid, and DL-tartaric acid) that all contain two carboxyl groups but different numbers of hydroxyl groups, with the aim of understanding whether and how the number of hydroxyl groups in these organic acids influences the Al state and acidity of the resulting beta zeolites and laying a fundamental basis for developing a zeolite beta based catalyst for removing organic acids from bio-oils via their esterification reactions with alcohols.

\section{Experimental}

\subsection{Modifications of beta zeolites}

A parent zeolite beta in protonic form (H-beta, $\mathrm{SiO}_{2} / \mathrm{Al}_{2} \mathrm{O}_{3}(\mathrm{~mol}$ $\left.\mathrm{mol}^{-1}\right)=21$, Catalyst Plant of Nankai University, PR China) was treated with a $0.1 \mathrm{M}$ solution of oxalic acid ( $\geq 98 \mathrm{wt} \%$, Beijing Chemworks, PR China), DL-malic acid ( $\geq 99.0 \mathrm{wt} \%$, Aladdin) and DL-tartaric acid (AR, Aladdin), respectively, at $333 \mathrm{~K}$ for $4 \mathrm{~h}$, repeatedly filtrated and washed with deionized water until the effluent water became neutral, and finally dried at $393 \mathrm{~K}$ for $6 \mathrm{~h}$ to obtain three modified $\mathrm{H}$-beta zeolites denoted by O-beta, M- beta and T-beta, respectively. All of the above samples were stored in a drier over a saturated $\mathrm{CaCl}_{2}$ solution to equilibrate with water vapor.

\subsection{Catalytic tests}

Catalysts were made by crushing the zeolite samples into particles of size 20-40 mesh. For comparison purpose, a resin catalyst Amberlyst ${ }^{\circledR} 15$ (A15, dry, exchange capacity $\geq 4.70$ eq. $\mathrm{kg}^{-1}$, Rome \& Hass) that is widely applied as esterification catalyst in industry was used as a reference catalyst.

The esterification reaction of acetic acid ( $\geq 99.5 \mathrm{wt} \%$, Aladdin) with $s e c$-butyl alcohol ( $\geq 99 \mathrm{wt} \%$, Aladdin), which was used as a model reaction representing the stabilization of biooils, was performed in a continuously flowing tubular fixedbed microreactor of internal diameter $14.0 \mathrm{~mm}$ and length 650 $\mathrm{mm}$ made from a 316L stainless steel pipe. During catalytic test, $3.0 \mathrm{~g}$ of a catalyst sample or A15 were packed in the middle of the reactor and fixed between a layer of quart spheres with a diameter of $2 \mathrm{~mm}$ in the bottom and a layer of quartz sands in the top.

A mixture of acetic acid and sec-butyl alcohol in a molar ratio of $1: 2$ was pumped into the reactor by a mass flowmeter at a weight hourly space velocity (WHSV) of $0.8 \mathrm{~h}^{-1}$ and heated to $393 \mathrm{~K}$. The reaction pressure was controlled at $2.5 \mathrm{MPa}$ by passing nitrogen through the reactor. The esterification products were analyzed with a SP-3420A gas chromatograph (GC) installed with a PEG-20M column $(30 \mathrm{~m} \times 0.25 \mathrm{~mm} \times 0.25 \mu \mathrm{m})$ and a flame ionization detector. The analysis results were calculated by using acetone (AR, Beijing Chemical Reagent Co., PR China) as the internal standard. ${ }^{29}$ The fractional conversion $\left(X_{\mathrm{AA}}\right)$ of acetic acid, the selectivity $\left(S_{\mathrm{SBAC}}\right)$ to sec-butyl acetate (SBAC) and the yield ( $\left.Y_{\mathrm{SBAC}}\right)$ of SBAC were calculated as follows:

$$
X_{\mathrm{AA}}(\%)=\frac{n_{\text {acetic acid in feed }}-n_{\text {acetic acid in product }}}{n_{\text {acetic acid in feed }}} \times 100
$$

$$
S_{\mathrm{SBAC}}(\%)=\frac{n_{\mathrm{SBAC}}}{n_{\mathrm{SBAC}}+n_{\text {sec-butyl ether }}+n_{\text {methyl ethyl ketone }}} \times 100
$$

$$
Y_{\mathrm{SBAC}}(\%)=X_{\mathrm{AA}} \times S_{\mathrm{SBAC}} \times 100
$$

where $n_{\text {acetic acid in feed }}$ and $n_{\text {acetic acid in product }}$ are the moles of acetic acid in the feed and product, respectively; $n_{\mathrm{SBAC}}, n_{\text {sec-butyl }}$

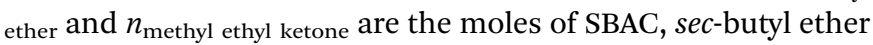
and methyl ethyl ketone in the product, respectively.

\subsection{Characterizations}

Detailed information on characterizations can be found in the ESI. $\dagger$

\section{Results and discussion}

\subsection{Bulk and surface chemical compositions: FTIR, XRF and} XPS characterizations

The skeletal vibration FTIR spectra of the beta zeolites are shown in Fig. 1. The absorption bands at 525 and $575 \mathrm{~cm}^{-1}$ are 


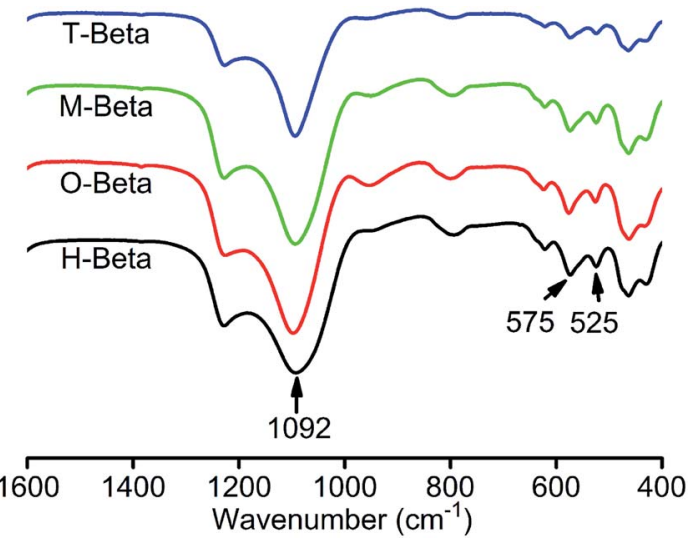

Fig. 1 FTIR spectra of $\mathrm{H}$-beta, $\mathrm{O}$-beta, $\mathrm{M}$-beta and $\mathrm{T}$-beta in the region of framework vibrations.

characteristic of zeolite beta due to the presence of five- and sixmembered rings in the structure. ${ }^{30}$ The band at about 1092 $\mathrm{cm}^{-1}$ represents the O-T-O asymmetric stretching vibration $\left(\nu_{\mathrm{a}(\text { Ото })}\right)$ which is sensitive to the content of framework aluminum; more exactly, this wavenumber increases with the decreasing aluminum content in the zeolite structure, therefore the shift of this wavenumber indicates the change in the framework molar Si/Al ratio. ${ }^{31}$ As seen in Fig. 1 and Table 1, $\nu_{\text {a(Ото) }}$ appearing at $1092 \mathrm{~cm}^{-1}$ for H-beta shifts to higher wavenumbers at 1098, 1094 and $1094 \mathrm{~cm}^{-1}$ for O-beta, M-beta and T-beta, respectively, indicating the decreased content of framework aluminum. This should be ascribed to the leaching of framework aluminum species by the organic acids that results in the increased framework molar $\mathrm{Si} / \mathrm{Al}$ ratios. Because the acidity of oxalic acid is the strongest among the three organic acid, the most decreased framework aluminum content of O-beta should be related to the strongest dealumination ability of oxalic acid. Interestingly, although the acidity of tartaric acid is stronger than that of malic acid, $\nu_{\mathrm{a}(\text { Ото) }}$ for T-beta is identical to that for M-beta, so there may be other phenomenon accompanied with dealumination.

XRF analysis of zeolites can provide the information on the bulk $\mathrm{SiO}_{2}$ and $\mathrm{Al}_{2} \mathrm{O}_{3}$ contents. Table 1 shows that the bulk molar $\mathrm{Si} / \mathrm{Al}$ ratios of the beta zeolites increase after the organic acid treatments and are in the order of O-beta $>$ T-beta $>$ M-beta, which exactly matches with the acidity order of the three organic acids (oxalic acid (0 hydroxyl group) $>$ tartaric acid (two hydroxyl groups) > malic acid (one hydroxyl group)). This signifies that the bulk molar Si/Al ratios of the acid-leached beta zeolites increase with the increasing acidity of the organic acids used. The FTIR results show that the framework molar Si/Al ratio of T-beta is identical to that of M-beta, while the XRF analysis results reveal that the bulk molar Si/Al ratio of T-beta is higher than that of M-beta, suggesting that more extraframework $\mathrm{Al}$ species are removed from T-beta than from M-beta.

One most important feature responsible for the enhanced catalytic performance of beta zeolite is the presence of aluminum gradient across the zeolite crystals..$^{32}$ For this reason, XPS measurements were performed to study the aluminum gradients in the different samples and the results are presented in Table 1. In Table 1, the $(\mathrm{Si} / \mathrm{Al})_{\text {surf }} /(\mathrm{Si} / \mathrm{Al})_{\text {bulk }}$ values indicating $\mathrm{Al}$ excess or deficiency on crystal surface compared with in the bulk phase are also given. It can be seen that: the value of ( $\mathrm{Si} /$ $\mathrm{Al})_{\text {surf }} /(\mathrm{Si} / \mathrm{Al})_{\text {bulk }}$ for $\mathrm{H}$-beta is about 1, indicating that aluminum atoms are uniformly distributed in the zeolite; however, the values of $(\mathrm{Si} / \mathrm{Al})_{\text {surf }} /(\mathrm{Si} / \mathrm{Al})_{\text {bulk }}$ for O-beta and M-beta decrease to 0.56 and 0.92 , respectively, demonstrating the preferential dealumination from the zeolite surface. This can be rationalized by the preferential attack of the zeolite outer surface by hydrogen ions in the acidic media. Interestingly, the value of (Si/ $\mathrm{Al})_{\text {surf }} /(\mathrm{Si} / \mathrm{Al})_{\text {bulk }}$ for T-beta remained at about 1 , in contrast to the intuition that the stronger acidity of tartaric acid than malic acid should have given a lower value of $(\mathrm{Si} / \mathrm{Al})_{\text {surf }} /(\mathrm{Si} / \mathrm{Al})_{\text {bulk }}$ than that of M-beta. It is speculated that this is because of the reinsertion of partial aluminum atoms in the solution that were removed from the zeolite structure into the zeolite framework on the external surface, which will be further discussed below.

\subsection{States of Al in beta zeolites}

The properties and catalytic performance of zeolites depend on the state of $\mathrm{Al}$ species in them, therefore the study of the $\mathrm{Al}$ coordination state is needed. ${ }^{33}{ }^{27} \mathrm{Al}$ (MQ) MAS NMR spectroscopy is known as an efficient tool to determine the coordination and local structure of aluminum atoms in zeolitic materials. ${ }^{34}$

The one-dimensional (1D) ${ }^{27} \mathrm{Al}$ MAS NMR spectra of H-beta and its derived samples are shown in Fig. 2. In the spectrum of $\mathrm{H}$-beta, there are an intense and sharp peak at about $53 \mathrm{ppm}$ ascribed to aluminum atoms in tetrahedral coordination and a signal at about $0 \mathrm{ppm}$ assigned to octahedrally coordinated aluminum atoms. Fig. 3(a) shows the corresponding twodimensional (2D) ${ }^{27} \mathrm{Al}$ MQ MAS NMR spectrum of H-beta in the form of contour plot, with the $1 \mathrm{D}^{27} \mathrm{Al}$ MAS NMR spectrum

Table 1 Chemical compositions of $\mathrm{H}$-beta, O-beta, $\mathrm{M}$-beta and T-beta

\begin{tabular}{|c|c|c|c|c|c|c|c|c|c|}
\hline \multirow[b]{2}{*}{ Entry } & \multirow[b]{2}{*}{ Sample } & \multirow[b]{2}{*}{$\nu_{\mathrm{a}(\text { Ото })}^{a}\left(\mathrm{~cm}^{-1}\right)$} & \multicolumn{3}{|c|}{ Bulk composition $^{b}$} & \multicolumn{3}{|c|}{ Surface composition $^{c}$} & \multirow[b]{2}{*}{$(\mathrm{Si} / \mathrm{Al})_{\text {surf }} /(\mathrm{Si} / \mathrm{Al})_{\text {bulk }}$} \\
\hline & & & $\mathrm{SiO}_{2}(\mathrm{wt} \%)$ & $\mathrm{Al}_{2} \mathrm{O}_{3}(\mathrm{wt} \%)$ & $(\mathrm{Si} / \mathrm{Al})_{\text {bulk }}$ & Si 2p & $\mathrm{Al} \mathrm{2p}$ & $(\mathrm{Si} / \mathrm{Al})_{\text {surf }}$ & \\
\hline 1 & H-Beta & 1092 & 92.02 & 7.42 & 10.5 & 29.18 & 2.58 & 11.31 & 1.08 \\
\hline 2 & O-Beta & 1098 & 98.87 & 1.08 & 77.5 & 30.48 & 0.70 & 43.54 & 0.56 \\
\hline 3 & M-Beta & 1094 & 95.09 & 4.75 & 17.0 & 29.71 & 1.89 & 15.72 & 0.92 \\
\hline 4 & T-Beta & 1094 & 96.00 & 3.81 & 21.4 & 29.93 & 1.37 & 21.85 & 1.02 \\
\hline
\end{tabular}

${ }^{a}$ Evaluated from Fig. 1 according to $\nu_{\mathrm{a}(\text { Ото })}{ }^{b}$ Calculated from XRF data. ${ }^{c}$ Calculated from XPS data. 


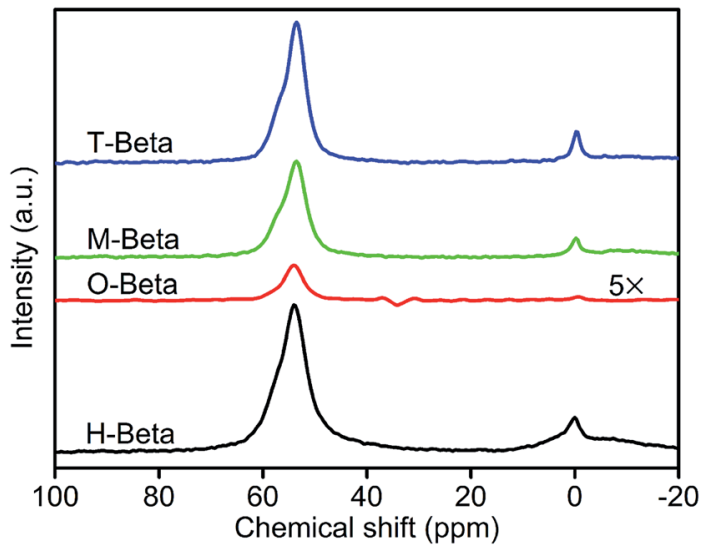

Fig. $2{ }^{27}$ Al NMR MAS spectra of $\mathrm{H}$-beta, O-beta, M-beta and T-beta.

being put on the top. The projection of the 2D spectrum along F1 axis represents the pure isotropic spectrum, free from anisotropic quadrupolar broadening. ${ }^{35}$ The tetrahedral region between 53 and 65 ppm consists of at least two components, $\mathrm{Al}(\mathrm{Iv})_{\mathrm{a}}$ and $\mathrm{Al}(\mathrm{Iv})_{\mathrm{b}}$, which are well-resolved in the isotropic dimension. They resonate close to the diagonal, indicating a small quadrupolar induced shift (Table 2) and being typical of aluminum in a crystalline silicoaluminate framework. According to the literature, ${ }^{36}$ they can be assigned to aluminum atoms occupying different T-sites: the peak $\mathrm{Al}(\mathrm{Iv})_{\mathrm{b}}$ is assigned to aluminum atoms on positions $\mathrm{T} 1$ and $\mathrm{T} 2$ in the framework of zeolite beta, and the peak $\mathrm{Al}(\mathrm{Iv})_{\mathrm{a}}$ corresponds to aluminum positioned in T3-T9 sites. An indication of a third tetrahedral species, $\mathrm{Al}(\mathrm{Iv})_{\mathrm{c}}$, is visible in the isotropic dimension, which is characterized by a strong quadrupolar interaction. This species may be locally distorted aluminum atoms associated with defective sites in the beta framework, or extra-framework amorphous aluminum-oxide species which were formed during the removal of template at high temperature or the process converting the zeolite into protonic form. ${ }^{26}$ Two resonances are seen in the octahedral region. The sharp octahedral peak represented by $\mathrm{Al}(\mathrm{VI})_{\mathrm{a}}$ has been ascribed to framework connected octahedral aluminums formed by partial hydrolysis. ${ }^{37,38}$ These octahedral Al atoms show a weak quadrupolar interaction and a small distribution in the isotropic chemical shifts (Table 2). However, the resonance $\mathrm{Al}(\mathrm{vI})_{\mathrm{b}}$ which is a weak signal shows strong quadrupolar interaction and is associated with highly distorted aluminum atoms. Table 2(a) and (b) gives the deconvolution results of the ${ }^{27} \mathrm{Al}(\mathrm{MQ})$ MAS NMR spectra to understand the change of Al sites in the beta zeolites. From the table, it is also noted whether these species are of framework
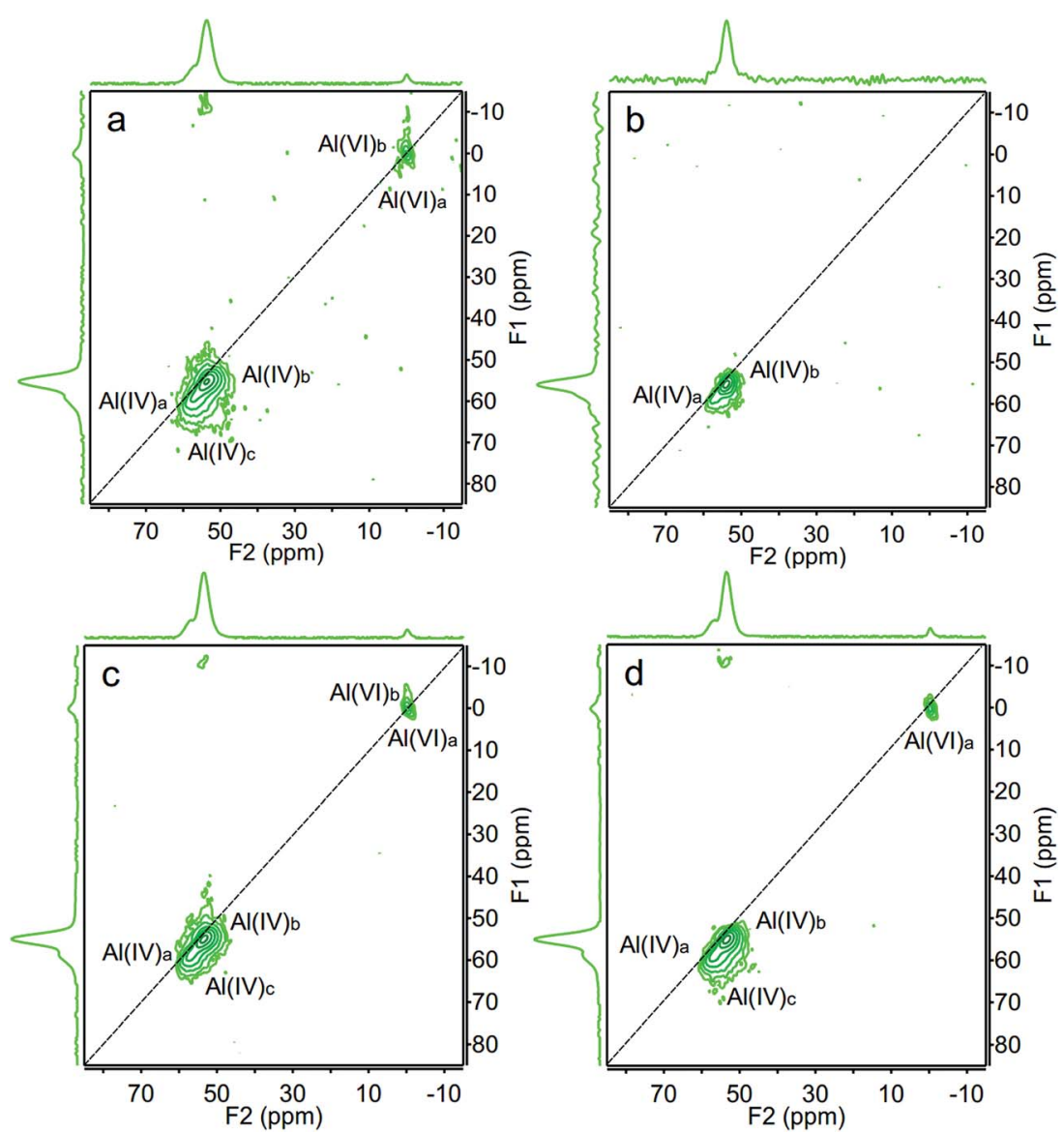

Fig. $3{ }^{27} \mathrm{Al} \mathrm{MQ}$ MAS NMR spectra of (a) H-beta, (b) O-beta, (c) M-beta, and (d) T-beta, in which the corresponding ${ }^{27}$ Al MAS NMR spectra are given on the top of each figure. The F1 projection represents the pure isotropic spectrum. 
Table 2 NMR parameters and relative Al contents determined by ${ }^{27} \mathrm{Al}$ (MQ) MAS NMR

(a) Peak parameters determined from the spectra

\begin{tabular}{llll}
\hline Entry & Peak & $\begin{array}{l}\text { Isotropic chemical } \\
\text { shift (ppm) }\end{array}$ & $\begin{array}{l}\text { Quadrupolar coupling } \\
\text { constant (MHz) }\end{array}$ \\
\hline 1 & $\operatorname{Al}(\mathrm{Iv})_{\mathrm{a}}$ & 58.7 & 2.2 \\
2 & $\mathrm{Al}(\mathrm{Iv})_{\mathrm{b}}$ & 54.7 & 1.9 \\
3 & $\mathrm{Al}(\mathrm{Iv})_{\mathrm{c}}$ & 59.1 & 5.5 \\
4 & $\mathrm{Al}(\mathrm{vI})_{\mathrm{a}}$ & -0.1 & 0.25 \\
5 & $\mathrm{Al}(\mathrm{vv})_{\mathrm{b}}$ & 2.3 & 5 \\
\hline
\end{tabular}

(b) Relative peak intensities of the spectra of beta zeolites

\begin{tabular}{|c|c|c|c|c|c|c|c|c|}
\hline Entry & Sample & $\begin{array}{l}\text { Peak Al(Iv) } \\
\text { FW }^{a}\end{array}$ & $\begin{array}{l}\text { Peak Al(IV) })_{b} \\
\text { FW }\end{array}$ & $\begin{array}{l}\text { Peak Al(IV) } \\
\text { N-FW }\end{array}$ & $\begin{array}{l}\text { Peak Al(vi)a } \\
\text { FW }\end{array}$ & $\begin{array}{l}\text { Peak Al(vi) } \\
\text { N-FW }\end{array}$ & $\begin{array}{l}\text { Relative total } \\
\text { intensity }\end{array}$ & $\begin{array}{l}\text { Ratio } \mathrm{Al}(\mathrm{IV})_{\mathrm{a}} / \\
\mathrm{Al}(\mathrm{IV})_{\mathrm{b}}\end{array}$ \\
\hline 1 & H-Beta & 21.51 & 62.74 & 7.17 & 2.43 & 6.15 & 1.00 & 0.34 \\
\hline 3 & M-Beta & 23.86 & 63.64 & 5.68 & 2.84 & 3.98 & 0.59 & 0.38 \\
\hline 4 & T-Beta & 26.47 & 63.53 & 4.12 & 5.88 & 0.00 & 0.77 & 0.42 \\
\hline
\end{tabular}

${ }^{a}$ Framework. ${ }^{b}$ Extra-framework.

(FW) or non-framework (N-FW) in nature. A typical fit illustrated in Fig. S1† shows excellent agreement between the data and fit.

Fig. 2 shows that the overall intensity of the spectrum of Obeta obtained by leaching with the solution of oxalic acid significantly diminishes. This indicates that a plenty of aluminum atoms are removed from O-beta, consistent with the higher molar Si/Al ratio (77.5) of O-beta obtained by the XRF characterization. Through the oxalic acid leaching, framework octahedral species $\mathrm{Al}(\mathrm{VI})_{\mathrm{a}}$, extra-framework octahedral species $\mathrm{Al}(\mathrm{VI})_{\mathrm{b}}$ and tetrahedral species $\mathrm{Al}(\mathrm{Iv})_{\mathrm{c}}$ are completely removed, and a considerable quantity of the framework tetrahedral species $\mathrm{Al}(\mathrm{IV})_{\mathrm{a}}$ and $\mathrm{Al}(\mathrm{IV})_{\mathrm{b}}$ are extracted, as revealed by the ${ }^{27} \mathrm{Al}$ MQ MAS NMR characterization results (Fig. 3 and Table 2). Moreover, the obvious decrease in the amount of $\mathrm{Al}(\mathrm{IV})_{\mathrm{a}}$ species indicates that the oxalic acid treatment preferentially removes aluminum atoms from crystallographic positions represented by $\mathrm{Al}(\mathrm{IV})_{\mathrm{a}}$. This is consistent with the previous results reporting that $\mathrm{Al}(\mathrm{Iv})_{\mathrm{a}}$ species were partially dealuminated by hydrothermal treatment at high temperature ${ }^{36}$ and that $\mathrm{Al}(\mathrm{IV})_{\mathrm{a}}$ species were preferentially leached by washing beta zeolite with a $1 \mathrm{M}$ hydrochloric acid solution. ${ }^{26}$ The $\mathrm{Al}(\mathrm{IV})_{\mathrm{a}}$ species corresponding to aluminum atoms positioned at T3-T9 sites are assigned to aluminum atoms partially connected to the framework representing lattice defective sites in zeolite $\mathrm{H}$-beta. It was reported that the $\mathrm{Al}(\mathrm{IV})_{\mathrm{b}}$ species corresponding to aluminum atoms in $\mathrm{T} 1$ and $\mathrm{T} 2$ sites appeared to be more resistant to nitric acid treatment than those in T3-T9 sites, and it seems that the latter sites are present in four-membered rings, which exhibit the smallest strain with the lowest $\mathrm{T}-\mathrm{O}-\mathrm{T}$ angle allowing the easier removal of $\mathrm{Al}$ atoms from these sites. ${ }^{35}$

Fig. 2 also shows that the overall intensity of the spectra of M-beta and T-beta obtained by leaching with the solutions of malic acid and tartaric acid, respectively, does not obviously decrease, and the ${ }^{27} \mathrm{Al}$ MQ MAS NMR spectra of M-beta and T- beta are similar to that of H-beta (Fig. 3), although they have changed relative intensity of the peaks (Table 2). The malic acid and tartaric acid treatments result in the decreases of extraframework tetrahedral species $\mathrm{Al}(\mathrm{Iv})_{\mathrm{c}}$ and the distorted octahedrally coordinated species $\mathrm{Al}(\mathrm{VI})_{\mathrm{b}}$, whereas traces of octahedrally coordinated framework species $\mathrm{Al}(\mathrm{VI})_{\mathrm{a}}$ are still present. As reported in literature ${ }^{39}$ the decreases in the contents of $\mathrm{Al}(\mathrm{IV})_{\mathrm{c}}$ and $\mathrm{Al}(\mathrm{VI})_{\mathrm{a}}$ indicated that the treatment with the solution of organic acid removed aluminum atoms preferentially from tetrahedrally coordinated extra-framework species represented by $\mathrm{Al}(\mathrm{IV})_{\mathrm{c}}$ and distorted octahedrally coordinated framework species characterized by $\mathrm{Al}(\mathrm{VI})_{\mathrm{a}}$. It was also reported that the $\mathrm{Al}(\mathrm{Iv})_{\mathrm{a}}$ species changed the coordination to octahedral upon partial hydrolysis while maintaining the connection with the framework. The malic acid (with one hydroxyl group) and tartaric acid (with two hydroxyl groups) treatments increase the relative content of the framework tetrahedral species $\mathrm{Al}(\mathrm{IV})_{\mathrm{a}}$ of the resulting samples, indicating their realumination effect on $\mathrm{H}$-beta zeolite in addition to dealumination, in accordance with the result that the citric acid (with one hydroxyl group) treatment of zeolite beta have both dealumination and realumination functions. ${ }^{28}$

The above results reveal that the leaching of $\mathrm{H}$-beta with the solutions of the three organic acids does not result in the formation of any new aluminum species. The dominant process during the organic acid leaching is the partial removal of framework tetrahedral aluminums represented by peaks $\mathrm{Al}(\mathrm{IV})_{\mathrm{a}}$ and $\mathrm{Al}(\mathrm{IV})_{\mathrm{b}}$. Table 2(b) compares the ratios of the two resonances corresponding to framework tetrahedral aluminums $\mathrm{Al}(\mathrm{IV})_{\mathrm{a}}$ and $\mathrm{Al}(\mathrm{IV})_{\mathrm{b}}$ as determined from the isotropic dimension spectra of the zeolite samples (Fig. 3). The ratio of $\mathrm{Al}(\mathrm{IV})_{\mathrm{a}} / \mathrm{Al}(\mathrm{Iv})_{\mathrm{b}}$ from 0.34 for $\mathrm{H}$-beta decreases to 0.12 for O-beta, but rises back to 0.38 for M-beta and 0.42 for T-beta. The higher ratios of $\mathrm{Al}(\mathrm{IV})_{\mathrm{a}} / \mathrm{Al}(\mathrm{IV})_{\mathrm{b}}$ of M-beta and T-beta than H-beta confirm that aluminum atoms 
were incorporated into the defect sites of the framework and transformed into $\mathrm{Al}(\mathrm{Iv})_{\mathrm{a}}$ species. It is worth noting that tartaric acid with two hydroxyl groups has stronger acidity than malic acid with one hydroxyl group, but they resulted in M-beta and Tbeta with the identical framework molar $\mathrm{Si} / \mathrm{Al}$ ratio, with the framework Al content of T-beta being higher than that of M-beta and therefore concluding the stronger realumination ability of tartaric acid than malic acid.

\subsection{Phase structure, textural property and acidity characterizations}

3.3.1 XRD characterization. Fig. 4 gives the XRD patterns of the different beta zeolites. It can be seen that, similar to the parent H-beta zeolite, all of the organic acid leached samples have the XRD patterns displaying representative Bragg reflections corresponding to the typical BEA zeolite topology ${ }^{40,41}$ and all have well-maintained crystalline structure, in agreement with the literature results for acid leached beta zeolites. ${ }^{39}$ It is well known that the distinct signal at $2 \theta=6.5-8.5^{\circ}$ ascribed to (101) reflection is an indication of a highly distorted structure due to the presence of different isomorphs in the zeolite structure. ${ }^{42,43}$ The relatively wider full widths at half-maxima of the diffraction peaks at $2 \theta=7.72^{\circ}$ and $22.52^{\circ}$ signify that the zeolite beta employed in this work has a smaller crystal size. ${ }^{44}$

The narrow main diffraction peak near $22-23^{\circ}$ ascribed to (302) reflection is generally taken as an evidence of lattice contraction/expansion of the beta structure. ${ }^{45}$ As seen in Fig. 4 and Table $\mathrm{S} 1, \uparrow$ for the parent $\mathrm{H}$-beta zeolite, the narrow main diffraction peak is at $22.52^{\circ}$ and the corresponding $d_{302}$ spacing is $3.945 \AA$; for the oxalic acid leached sample O-beta, this peak shifts to $22.60^{\circ}$ and the corresponding $d_{302}$ spacing decreases to $3.932 \AA$, indicating some relaxation of the BEA matrix and suggesting the removal of aluminum atoms from zeolite framework in a great degree ${ }^{46}$ and for the malic acid leached sample M-beta and tartaric acid leached sample T-beta, this peak shifts to $22.54^{\circ}$ and the corresponding $d_{302}$ spacing decreases to $3.941 \AA$, indicating the slight relaxation of the BEA

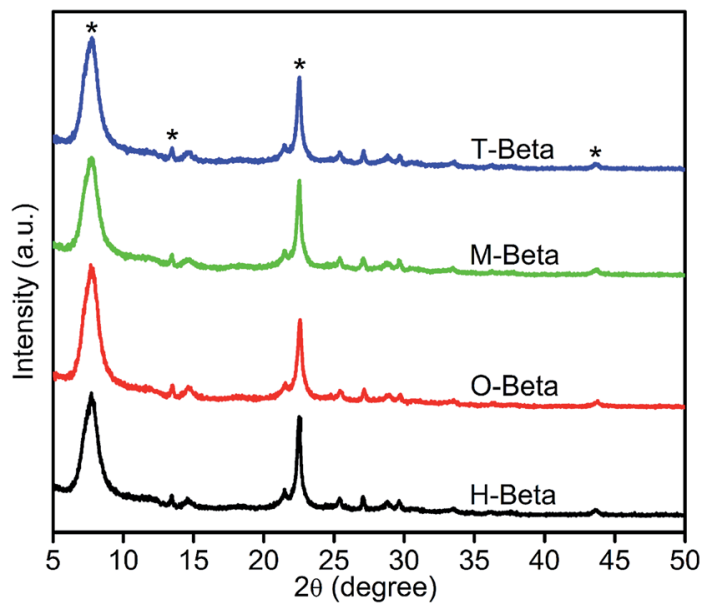

Fig. 4 XRD patterns of $\mathrm{H}$-beta, O-beta, M-beta and T-beta zeolites. The asterisks refer to the reflections listed in Table S1. $\dagger$ matrix and the removal of partial aluminum atoms from the zeolite framework. Therefore, the framework molar Si/Al ratio is in the order of O-beta $>$ M-beta $=$ T-beta $>\mathrm{H}$-beta, consistent with the FTIR results. It is noticed that, although the acidity of tartaric acid is stronger than that of malic acid, they have the identical leaching effect on the zeolite structure, as reflected by the identical $2 \theta$ and $d$ values of M-beta and T-beta for the (302) reflection. This further confirms the stronger realumination ability of tartaric acid than malic acid.

3.3.2 Pore structure characterization. The nitrogen adsorption-desorption isotherms of $\mathrm{H}$-beta and the organic acid leached beta zeolites are shown in Fig. S2. $\dagger$ They all exhibit a type IV isotherm with a hysteresis loop. The BET specific surface areas and pore volumes of the different beta zeolites are given in Table 3. It can be seen that the three organic acids leached samples have obvious increases in BET surface area and micropore volume due to the removal and/or reinsertion of extra-framework Al species that endow the resulting zeolites with opener pore channels and nearly intact crystallinity.

3.3.3 Acidity characterizations. To understand the effects of the different organic acid treatments on the acidity of the resulting beta zeolites, $\mathrm{NH}_{3}$-TPD and Py-IR measurements were carried out and the results are given in Fig. 5 and $\mathrm{S} 3 \dagger$ and Table 4.

Fig. 5 shows the $\mathrm{NH}_{3}$-TPD profiles of $\mathrm{H}$-beta and the organic acid leached beta zeolites. There exist two kinds of acid sites in H-beta: weak acid sites represented by a typical desorption peak at around $513 \mathrm{~K}$ and strong acid ones signified by a typical desorption peak at around $683 \mathrm{~K}$. Similar results were obtained for all of the modified samples. For the oxalic acid leached sample O-beta, the amount of weak acid and strong acid dramatically decreased, indicating the removal of aluminum atoms in a large amount; for the malic acid leached sample Mbeta and the tartaric acid leached sample T-beta, the amount of weak acid obviously decreased, but that of strong acid remained almost unchanged, possibly ascribed to the predominant removal of extra-framework $\mathrm{Al}$ species from the parent $\mathrm{H}$-beta zeolite by the treatments with organic acids with hydroxyl groups. $^{21}$

Fig. S3 $\uparrow$ shows the Py-IR spectra of H-beta and the organic acids leached samples in the region of $1575-1400 \mathrm{~cm}^{-1}$. It can be seen that there are three sharp bands due to $\mathrm{C}-\mathrm{C}$ stretching vibrations of pyridine, with the strong band at $1490 \mathrm{~cm}^{-1}$ assigned to pyridine molecules adsorbed on both Brönsted (B) and Lewis (L) acid sites, and those at 1540 and $1450 \mathrm{~cm}^{-1}$ to protonated pyridine molecules by $\mathrm{B}$ acid sites and pyridine molecules adsorbed on L acid sites, respectively. ${ }^{47}$ For organic acid leached beta zeolites, the intensity of all the bands at 1490 $\mathrm{cm}^{-1}$ is considerably weaker than that for H-beta, suggesting that the decreased total acid sites.

Table 4 presents the quantitative results of the Py-IR spectra. ${ }^{47}$ It can be seen that O-beta obtained by leaching $\mathrm{H}$ beta with the solution of oxalic acid has the largely decreased quantities of both $\mathrm{B}$ and $\mathrm{L}$ acids due to the massive removal of aluminum atoms from the zeolite. These results are in good agreement with those of Maache et $a l .{ }^{48}$ and Apelian et al. ${ }^{49}$ who reported the decreased quantities of B and L acids in H-beta 
Table 3 Textural properties of $\mathrm{H}$-beta, O-beta, $\mathrm{M}$-beta and T-beta ${ }^{a}$

\begin{tabular}{lllll}
\hline Entry & Sample & Specific surface area ${ }^{a}\left(\mathrm{~m}^{2} \mathrm{~g}^{-1}\right)$ & Micropore volume $^{b}\left(\mathrm{~cm}^{3} \mathrm{~g}^{-1}\right)$ & Total pore volume $^{c}\left(\mathrm{~cm}^{3} \mathrm{~g}^{-1}\right)$ \\
\hline 1 & H-Beta & 528 & 0.19 & 0.36 \\
2 & O-Beta & 591 & 0.22 & 0.40 \\
3 & M-Beta & 553 & 0.21 & 0.39 \\
4 & T-Beta & 563 & 0.20 & 0.39
\end{tabular}

${ }^{a}$ Calculated with the BET method. ${ }^{b}$ Calculated with the $t$-plot method. ${ }^{c}$ Calculated from nitrogen single point adsorption at $P / P_{0}=0.99$.

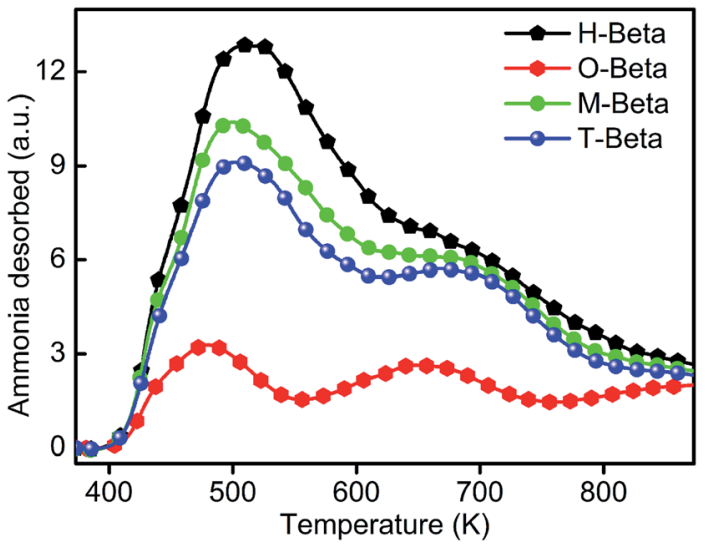

Fig. $5 \mathrm{NH}_{3}$-TPD profiles of $\mathrm{H}$-beta, O-beta, $\mathrm{M}$-beta and T-beta.

Table 4 Acid types and strength distributions of $\mathrm{H}$-beta, O-beta, $\mathrm{M}$ beta and T-beta

\begin{tabular}{|c|c|c|c|c|c|c|c|c|}
\hline \multirow[b]{3}{*}{ Entry } & \multirow[b]{3}{*}{ Sample } & \multicolumn{7}{|c|}{ Acidity $\left(\mu \mathrm{mol} \mathrm{g}^{-1}\right)$} \\
\hline & & \multicolumn{2}{|c|}{ Weak acid } & \multicolumn{2}{|c|}{$\begin{array}{l}\text { Medium } \\
\text { and strong } \\
\text { acid }\end{array}$} & \multicolumn{3}{|l|}{ Total } \\
\hline & & $\mathrm{L}$ & B & $\mathrm{L}$ & B & $\mathrm{L}$ & B & $\mathrm{L}+\mathrm{B}$ \\
\hline 1 & H-Beta & 40.0 & 98.8 & 203.5 & 68.3 & 243.5 & 167.1 & 410.6 \\
\hline 2 & O-Beta & 0.0 & 47.4 & 25.4 & 31.0 & 12.7 & 78.4 & $103.8^{a}$ \\
\hline 3 & M-Beta & 19.4 & 90.1 & 125.3 & 69.7 & 144.7 & 159.8 & 304.5 \\
\hline 4 & T-Beta & 6.6 & 75.3 & 91.6 & 78.6 & 98.2 & 153.9 & 252.1 \\
\hline
\end{tabular}

zeolites treated with inorganic acids such as $\mathrm{HCl}$ or organic acids such as dicarboxylic acid. Unexpectedly, the quantity of medium and strong L acid of O-beta is higher than that of total $\mathrm{L}$ acid, indicating the elimination of water that results in the conversion of two B acid sites into one $\mathrm{L}$ acid site at high temperature, as reported by Ward et al. ${ }^{50}$ The interconversion between $\mathrm{L}$ and $\mathrm{B}$ acid sites of aluminum atoms connected to the zeolite framework seems to be a characteristic of zeolite because of its rich structure defects. ${ }^{18}$

It can be also seen that M-beta and T-beta obtained by leaching $\mathrm{H}$-beta with the solution of malic acid and the solution of tartaric acid, respectively, have the increased quantity of medium and strong $\mathrm{B}$ acid, indicating the reinsertion of partial aluminum atoms into the framework and being in agreement with the results of Xie et $a l .{ }^{28}$ It was reported that the quantity of strong B acid of beta zeolite was increased and the distribution of aluminum atoms was changed, ascribed to the concurrence of dealumination and realumination during the citric acid treatment. T-Beta has a higher quantity of medium and strong B acid than M-beta, indicating that more aluminum atoms were reinserted into the framework of the former. In addition, Guisnet $e t a l . .^{51}$ and Sulikowski et $a .^{52}$ reported that, for zeolites mazzite and $\mathrm{Y}$, the framework $\mathrm{Si}(2 \mathrm{Al})$ site corresponding to $(\mathrm{SiO})_{2}(\mathrm{AlO}) \mathrm{Si}-\mathrm{OH}-\mathrm{Al}(\mathrm{OSi})_{3}$ is less acidic than the framework $\mathrm{Si}(1 \mathrm{Al})$ site corresponding to $(\mathrm{SiO})_{3} \mathrm{Si}-\mathrm{OH}-\mathrm{Al}(\mathrm{OSi})_{3}$. From this point of view, we can infer that the framework aluminum atoms of M-beta and T-beta at $\mathrm{Si}(2 \mathrm{Al})$ sites may be partially removed from the zeolite framework, and some aluminum species in the solutions of malic acid and tartaric acid were retransformed to framework $\mathrm{Si}(1 \mathrm{Al})$ species with the help of hydroxyl groups of the organic acids, therefore the quantities of medium and strong B acid of M-beta and T-beta are higher than that of $\mathrm{H}^{-}$ beta. Similarly, more framework aluminum atoms of H-beta at $\mathrm{Si}(2 \mathrm{Al})$ sites could be removed from its framework by tartaric acid that has stronger acidity than malic acid, and more aluminum species in the tartaric acid solution can be transformed into framework $\mathrm{Si}(1 \mathrm{Al})$ species with the help of more hydroxyl groups in the tartaric acid solution than in the solution malic acid, leading to the increased medium and strong B acidity of T-beta than M-beta.

In addition, in view of the significant change of the medium and strong B acidity caused by the organic acid treatments, the distribution of tetrahedrally coordinated framework $\mathrm{Al}$ species $\left(\mathrm{Al}(\mathrm{IV})_{\mathrm{a}} / \mathrm{Al}(\mathrm{IV})_{\mathrm{b}}\right)$ is correlated to the medium and strong B acidity

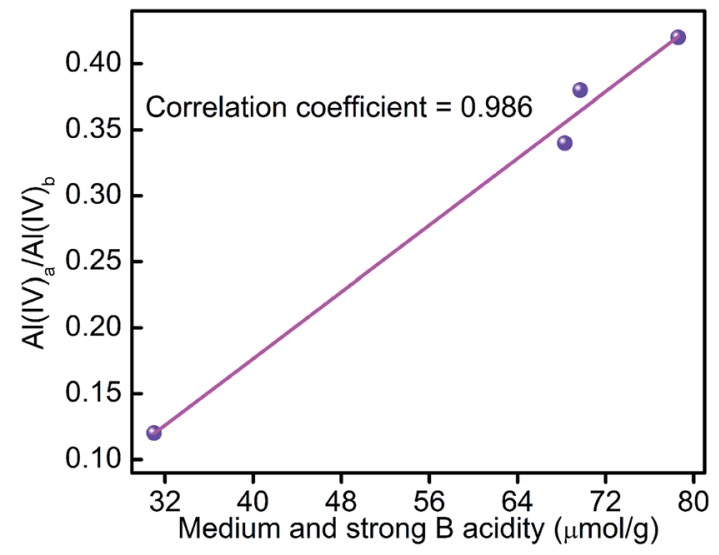

Fig. $6 \mathrm{Al}(\mathrm{IV})_{\mathrm{a}} / \mathrm{Al}(\mathrm{IV})_{\mathrm{b}}$ Vs. medium and strong B acidity. 
and the results are shown in Fig. 6. It can be seen that the medium and strong B acidity is closely related to the distribution of tetrahedrally coordinated framework species.

By combining these results and the ${ }^{27} \mathrm{Al}$ (MQ) MAS NMR results, it can be seen that, partial framework aluminum atoms were removed from the $\mathrm{H}$-beta zeolite during the organic acid treatments. Because extra-framework $\mathrm{Al}$ species in zeolites are responsible for weak acid sites, ${ }^{21}$ the decreased quantities of weak L and B acids of the beta zeolites after organic acid leaching (Table 4) indicate the extraction of most extraframework Al species from the zeolite pore channels. The oxalic acid leaching not only removes framework aluminum atoms from the zeolite framework in large amount but also brings them out of the zeolite pore channels leading to opener pore channels, i.e., the oxalic acid leaching has dual roles: the first is to hydrolyze Al-O-Si linkages (see step 1), and the second is as a chelating agent to complex the tetrahedral $\mathrm{Al}$ species and then to move the resulting species out of the pore channels (see step 2(a)). Similar observations were reported for the dealumination of beta zeolite using dicarboxylic acid $^{\mathbf{4 9}}$ and toluene4-sulfonic acid. ${ }^{53}$ On the whole, there is only dramatic dealumination during the oxalic acid (with no hydroxyl group) leaching.

Step 1:<smiles>C=C[SiH2]O[Si](O[SiH3])(O[SiH3])O[SiH3]</smiles><smiles>[Si]O[Al](O[Si])OS</smiles>

Step 2:

$\mathrm{Al}(\mathrm{OH})_{2}{ }^{+}+n\left[\mathrm{C}_{2} \mathrm{O}_{4}\right]^{2-} \rightleftharpoons \mathrm{Al}(\mathrm{OH})_{2}\left[\mathrm{C}_{2} \mathrm{O}_{4}\right]_{n}{ }^{1-2 n}(n=0,1,2,3 \ldots)$

$$
\begin{aligned}
\mathrm{Al}(\mathrm{OH})_{2}{ }^{+}+ & n\left[\mathrm{H}_{3} \mathrm{C}_{4} \mathrm{O}_{4}(\mathrm{OH})\right]^{2-} \rightleftharpoons \\
& \mathrm{Al}(\mathrm{OH})_{2}\left[\mathrm{H}_{3} \mathrm{C}_{4} \mathrm{O}_{4}(\mathrm{OH})\right]_{n}{ }^{1-2 n}(n=0,1,2,3 \ldots) \\
\mathrm{Al}(\mathrm{OH})_{2}{ }^{+}+ & n\left[\mathrm{H}_{2} \mathrm{C}_{4} \mathrm{O}_{4}(\mathrm{OH})_{2}\right]^{2-} \rightleftharpoons \\
& \mathrm{Al}(\mathrm{OH})_{2}\left[\mathrm{H}_{2} \mathrm{C}_{4} \mathrm{O}_{4}(\mathrm{OH})_{2}\right]_{n}{ }^{1-2 n}(n=0,1,2,3 \ldots)
\end{aligned}
$$

Step 3:

$$
\mathrm{Al}(\mathrm{OH})_{2}{ }^{+}+2 \mathrm{H}_{2} \mathrm{O} \rightleftharpoons \mathrm{Al}(\mathrm{OH})_{4}{ }^{-}
$$

Step 4:
As reported by Xie et al. ${ }^{28}$ the realumination mechanism of beta zeolite is isomorphous substitution when it is treated with citric acid (with one hydroxyl group), as encountered in the treatments with malic acid (with one hydroxyl group) and tartaric acid (with two hydroxyl groups). While malic acid and tartaric acid can also function as chelating agents to complex $\mathrm{Al}(\mathrm{OH})_{2}{ }^{+}$in the malic acid solution and tartaric acid solution formed in the dealumination step (see step 2(b) and (c)), their different numbers of $-\mathrm{OH}$ groups can reduce the chelating extent of the resulting $\mathrm{Al}$-malic acid complex and $\mathrm{Al}$-tartaric acid complex. ${ }^{28}$ Therefore, more $\mathrm{Al}(\mathrm{OH})_{2}{ }^{+}$cations in these solutions are hydrolyzed to produce $\mathrm{Al}(\mathrm{OH})_{4}{ }^{-}$anions (see step $3)$, then $\mathrm{Al}(\mathrm{OH})_{4}{ }^{-}$anions can be reinserted into the framework of beta zeolite at the defect sites (see step 4). On the one hand, more framework tetrahedral $\mathrm{Al}$ species were removed by tartaric acid leaching than by malic acid leaching, resulting in more $\mathrm{Al}(\mathrm{OH})_{2}{ }^{+}$cations in the tartaric acid solution at the first step, ascribing that the stronger acidity of tartaric acid; on the other hand, more $\mathrm{Al}(\mathrm{OH})_{4}{ }^{-}$anions were formed and reinserted into the framework of T-beta at the defect sites with the help of two hydroxyl groups. Here, we must emphasize that the malic acid and tartaric acid leaching plays a third role, i.e., providing more $\mathrm{Al}(\mathrm{OH})_{4}{ }^{-}$in the solutions for reinsertion into the zeolite framework, as illustrated in Scheme 1.

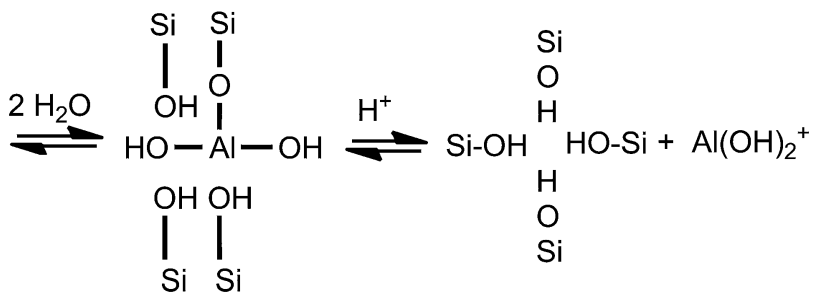

\subsection{Catalytic performance}

The ability of strong B acid sites in catalyzing esterification reaction has been demonstrated by the well-known macroporous cation exchange resin A15 with strong acidity, ${ }^{12}$ so A15 was used as the reference catalyst in the present investigation. Fig. 7 shows the values of $X_{\mathrm{AA}}, S_{\mathrm{SBAC}}$ and $Y_{\mathrm{SBAC}}$ obtained over A15 and the different beta zeolites. The values of $X_{\mathrm{AA}}$ and $Y_{\mathrm{SBAC}}$ for A15 are $42.8 \%$ and $32.6 \%$, respectively. The sole strong B acid sites of A15 can also serve as active centers for etherification, which makes the selectivity to the target product SBAC lower than $80 \%$, as shown in the GC-MS results in Fig. S4. $\dagger$

Compared with A15, all of the zeolites including the parent H-beta gave dramatically increased $X_{\mathrm{AA}}$ and significantly enhanced $S_{\mathrm{SBAC}}$, with T-beta giving the highest conversion and M-beta giving the highest selectivity. It is rational that the

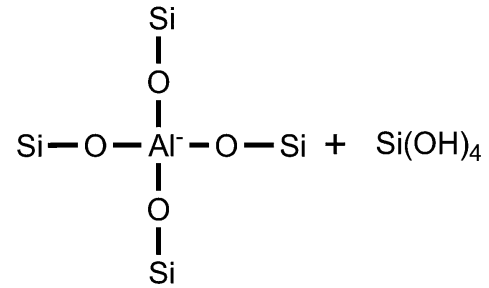




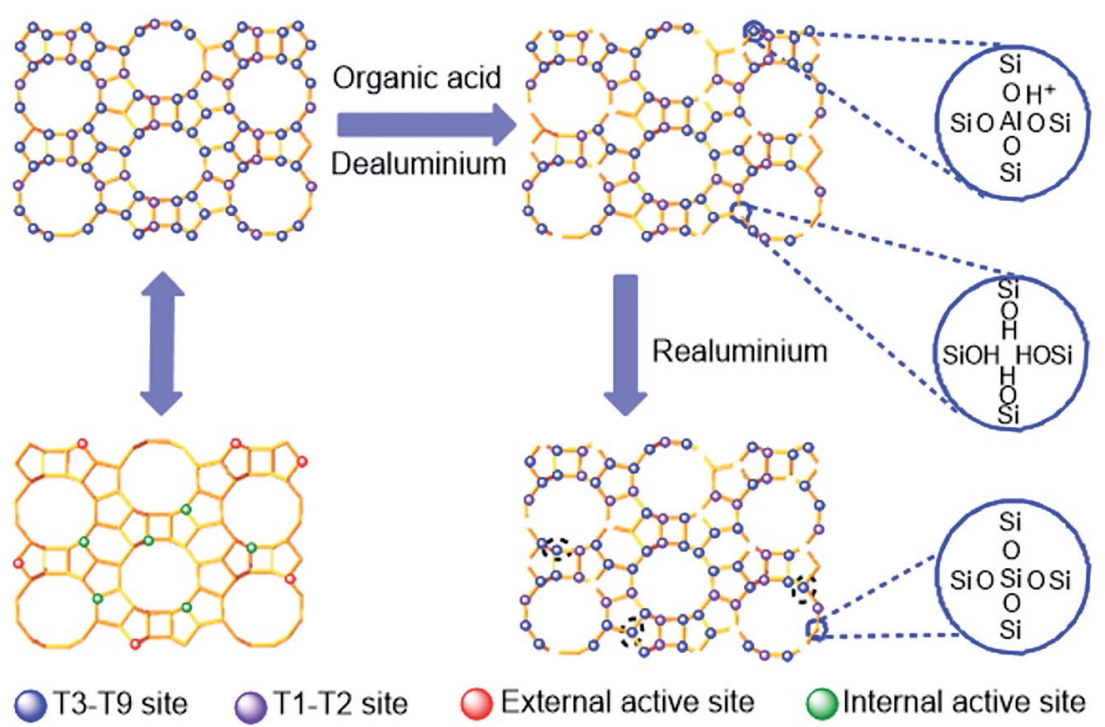

Scheme 1 Schematic representation of the dealumination and realumination mechanisms of beta zeolite via organic acid leaching.

enhanced selectivity obtained over the different zeolites can be ascribed to the confining effect of the pore channels $(6.6 \times 6.7$ $\AA^{2}$ along $a$ - and $b$-axis and $5.6 \times 5.6 \AA^{2}$ along $c$-axis) of the beta zeolites. ${ }^{54}$ With the increasing numbers of hydroxy groups of the organic acids used, $Y_{\mathrm{SBAC}}$ obtained over the resulting zeolites first increased and then dropped, with M-beta giving the highest $Y_{\mathrm{SBAC}}$. This can be attributed to the compromised dealumination and realumination abilities of malic acid leaching that provide the resultant $\mathrm{M}$-beta with ideal $\mathrm{Al}$ and acidity distributions.

It is surprising to see that all the beta zeolites especially those obtained by acid leaching gave much higher conversion rates despite their much weaker acidity than A15, which may be due to the synergistic effect of $\mathrm{B}$ and $\mathrm{L}$ acid sites in the zeolites. ${ }^{55}$ In view of the fact that A15 only has B acidity, it is conceived that, for the beta zeolites concerned here, B acidity should be mainly responsible for esterification activity. To validate this, the medium and strong B acidity of the different beta zeolites in

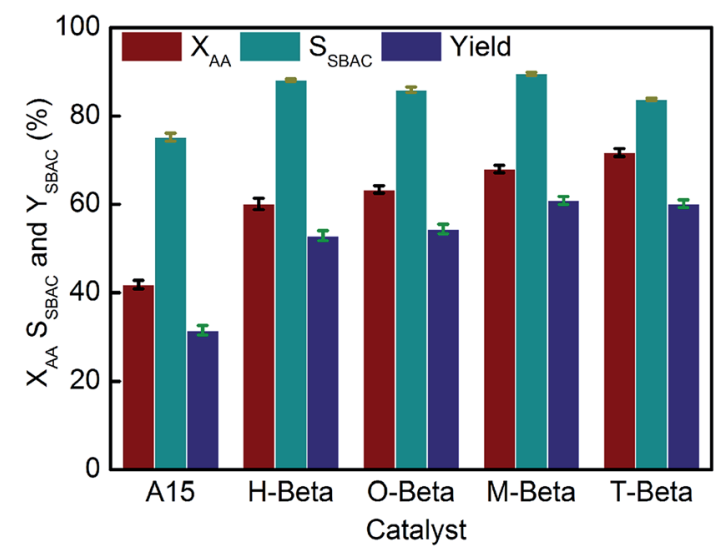

Fig. $7 X_{\mathrm{AA}}, \mathrm{S}_{\mathrm{SBAC}}$ and $Y_{\mathrm{SBAC}}$ of A15, H-beta, O-beta, M-beta and Tbeta.
Table 4 was correlated with $X_{\mathrm{AA}}$ and the results are shown in Fig. 8(a). Because the medium and strong B acidity is positively correlated to the distribution $\left(\mathrm{Al}(\mathrm{Iv})_{\mathrm{a}} / \mathrm{Al}(\mathrm{IV})_{\mathrm{b}}\right)$ of tetrahedrally coordinated framework $\mathrm{Al}$ species, the effect of $\mathrm{Al}(\mathrm{IV})_{\mathrm{a}} / \mathrm{Al}(\mathrm{IV})_{\mathrm{b}}$ on $X_{\mathrm{AA}}$ is also presented in Fig. 8(a). Unexpectedly, $X_{\mathrm{AA}}$ does not monotonically increase with the increasing quantity of medium and strong B acid, suggesting that the medium and strong B acid sites are not the sole factor affecting $X_{\mathrm{AA}}$. The medium and strong $\mathrm{B}$ acidity and $\mathrm{Al}(\mathrm{Iv})_{\mathrm{a}} / \mathrm{Al}(\mathrm{Iv})_{\mathrm{b}}$ of O-beta are lower than those of $\mathrm{H}$-beta, but $X_{\mathrm{AA}}$ obtained over O-beta is higher than that over $\mathrm{H}$-beta. This suggests that the $\mathrm{Al}(\mathrm{Iv})_{\mathrm{b}}$ atoms at $\mathrm{T} 1$ and $\mathrm{T} 2$ sites should be the main active sites for the esterification of sec-butyl alcohol with acetic acid.

As aforementioned, the presence of aluminum gradient across beta zeolite crystals is also an important factor accounting for the catalytic performance. To confirm this, the $(\mathrm{Si} / \mathrm{Al})_{\text {surf }} /(\mathrm{Si} / \mathrm{Al})_{\text {bulk }}$ values of the different beta zeolites in Table 1 were correlated with $X_{\mathrm{AA}}$ and the results are shown in Fig. 8(b). It is seen that $X_{\mathrm{AA}}$ first increases and then decreases with the increasing $(\mathrm{Si} / \mathrm{Al})_{\text {surf }} /(\mathrm{Si} / \mathrm{Al})_{\text {bulk }}$ ratio. This can be interpreted as follows: on the one hand, the chemical attack of hydrogen ions in the leaching solutions on the H-beta zeolite occurs preferentially at the outer surface of the H-beta zeolite that leads to the preferential extraction of extra-framework $\mathrm{Al}$ species on the outer surface of the zeolite particles and thereby the exposure of more framework Al species; on the other hand, the presence of hydroxyl groups in the malic acid and tartaric acid solutions promotes the reinsertion of aluminum species formed by leaching onto the outer surface of the zeolite framework, also leading to the increased aluminum gradient. Therefore, the values of $X_{\mathrm{AA}}$ obtained over M-beta and T-beta were higher than that of $\mathrm{H}$-beta and O-beta, with T-beta with more medium and strong B acid sites having higher $X_{\mathrm{AA}}$ than M-beta. As a result of it, the values of $X_{\mathrm{AA}}$ obtained over the different zeolites are in the order of T-beta $>$ M-beta $>$ O-beta $>$ H-beta. 


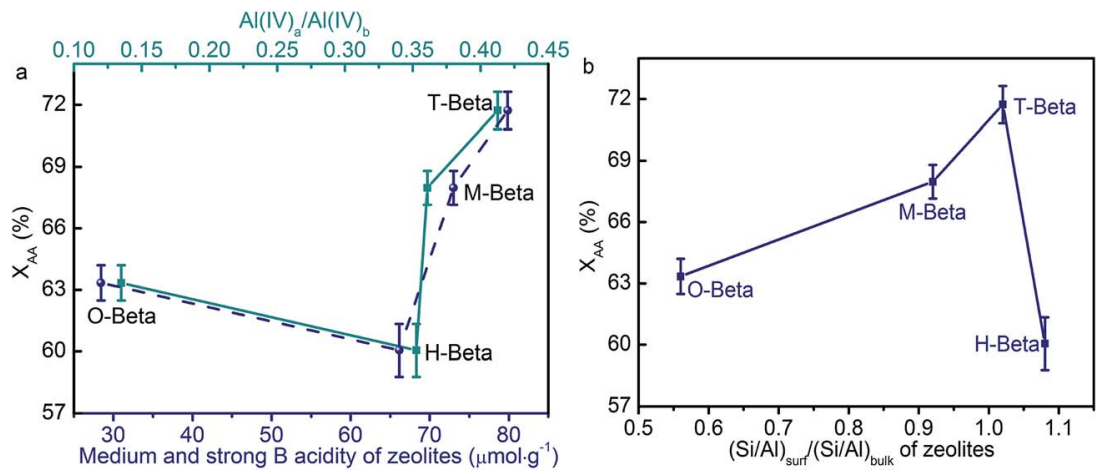

Fig. 8 Effects of medium and strong $\mathrm{B}$ acidity and $(\mathrm{Si} / \mathrm{All})_{\text {surf }} /(\mathrm{Si} / \mathrm{Al})_{\text {bulk }}$ of beta zeolites on $X_{\mathrm{AA}}$

Interestingly, we found that $S_{\mathrm{SBAC}}$ depends upon the density of medium and strong $\mathrm{B}$ acid sites over the beta zeolites, defined as medium and strong $\mathrm{B}$ acidity divided by total surface area. As seen in Fig. $9, S_{\text {SBAC }}$ presents a maximum with the increasing density of medium and strong $\mathrm{B}$ acid sites, indicating that a suitable density of medium and strong B acid sites is necessary for achieving an optimum $S_{\text {SBAC. }}$ It can also be seen that T-beta has the lowest $S_{\text {SBAC }}$ because of its highest density of medium and strong $\mathrm{B}$ acid sites and larger total pore volume that benefit the formation of the by-product sec-butyl ether. Among the three acids used, tartaric acid with two hydroxyl groups has the strongest dealumination and realumination abilities, resulting in the excessive quantity and overhigh density of medium and strong B acid sites of Tbeta and thus negatively impacting $S_{\mathrm{SBAC}}$ of the resulting Tbeta; whereas oxalic acid with no hydroxyl group has only dealumination ability without realumination ability, leading to the inadequate density of medium and strong $\mathrm{B}$ acid sites of O-beta, unfavorable for the formation of SBAC; distinctly, malic acid with one hydroxyl group owns compromised dealumination and realumination abilities, yielding a zeolite M-beta with appropriate quantity and density of medium and strong B acid sites and thereby the highest $S_{\mathrm{SBAC}}$, consistent with the results of Peters ${ }^{\mathbf{1 2}}$ who reported that the

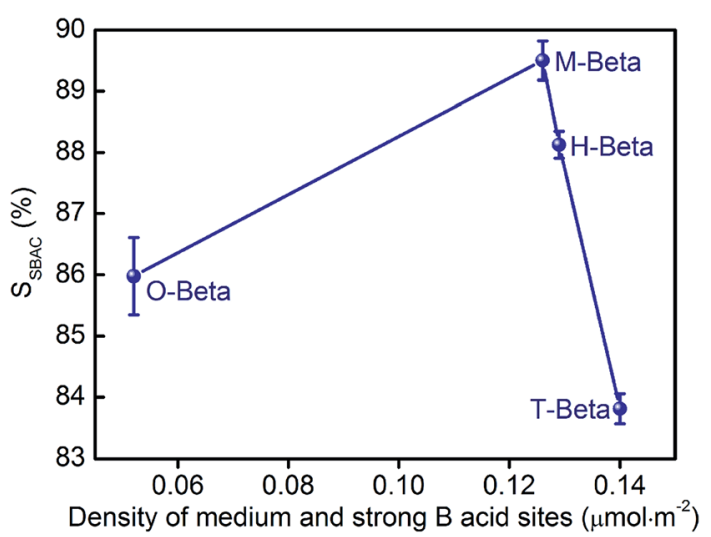

Fig. 9 Density of medium and strong acid B sites of the beta zeolites vs. $S_{\mathrm{SBAC}}$ sulphated zirconia showed an optimum calcination temperature for the esterification of acetic acid with butanol even both the amount and acidity of the acid sites increased monotonically with the increasing calcination temperature. The stability of M-beta in the esterification of acetic acid and secbutanol was tested and the results are shown in Fig. S5. $\dagger$ It can be seen that M-beta exhibited excellent stability after reaction for $104 \mathrm{~h}$.

\section{Conclusions}

H-Beta zeolites were modified by leaching with the organic acids with different numbers of hydroxyl groups, and the effects of hydroxyl group numbers in the different organic acids on the dealumination and realumination behavior of beta zeolite were comprehensively investigated. The characterization results showed that: the oxalic acid (with no hydroxyl group) leaching could only dealuminate the $\mathrm{Al}$ atoms at $\mathrm{Al}(\mathrm{IV})_{\mathrm{c}}, \mathrm{Al}(\mathrm{VI})_{\mathrm{a}}$, and $\mathrm{Al}(\mathrm{VI})_{\mathrm{b}}$ sites and massive framework tetrahedral $\mathrm{Al}$ atoms at $\mathrm{Al}(\mathrm{Iv})_{\mathrm{a}}$ and $\mathrm{Al}(\mathrm{IV})_{\mathrm{b}}$ sites, resulting in the decreased quantities of Lewis and Brönsted acids to a great degree, while the malic acid and tartaric acid leaching could not only partially dealuminate the $\mathrm{Al}$ atoms at the outer surface preferentially but also reinsert the $\mathrm{Al}(\mathrm{OH})_{2}{ }^{+}$species in the leaching solutions into the framework of beta zeolites at T3-T9 sites, with tartaric acid with two hydroxyl groups having higher realumination ability than malic acid with only one hydroxyl group. Among the three organic acid treated H-beta zeolites, the one obtained by malic acid leaching exhibited the best performance in catalyzing the esterification, attributed to its suitable quantity and density of medium and strong Brönsted acid sites and enhanced aluminum gradient. The malic acid treatment could be taken as an effective way to optimize the distribution of $\mathrm{Al}$ species in $\mathrm{H}$-beta zeolite and thus improve the catalytic performance of the resulting $\mathrm{H}$-beta zeolite.

\section{Acknowledgements}

We gratefully acknowledge the National Natural Science Foundation of China for providing financial support through grants U1462203 and 91434206. 


\section{Notes and references}

1 M. M. Antunes, P. Neves, A. Fernandes, S. Lima, A. F. Silva, M. F. Ribeiro, C. M. Silva, M. Pillinger and A. A. Valente, Catal. Sci. Technol., 2016, 6, 7812-7829.

2 G. W. Huber and A. Corma, Angew. Chem., Int. Ed., 2007, 46, 7184-7201.

3 M. Hara, Energy Environ. Sci., 2010, 3, 601-607.

4 S. Miao and B. H. Shanks, Appl. Catal., A, 2009, 359, 113-120.

5 J. Gangadwala, S. Mankar and S. Mahajani, Ind. Eng. Chem. Res., 2003, 42, 2146-2155.

6 N. Shibasaki-Kitakawa, K. Hiromori, T. Ihara, K. Nakashima and T. Yonemoto, Fuel, 2015, 139, 11-17.

7 S. K. Bhorodwaj and D. K. Dutta, Appl. Catal., A, 2010, 378, 221-226.

8 S. R. Kirumakki, N. Nagaraju and K. V. R. Chary, Appl. Catal., A, 2006, 299, 185-192.

9 J. Lilja, J. Wärnå, T. Salmi, L. J. Pettersson, J. Ahlkvist, H. Grénman, M. Rönnholm and D. Y. Murzin, Chem. Eng. J., 2005, 115, 1-12.

10 G. D. Yadav and P. H. Mehta, Ind. Eng. Chem. Res., 1994, 33, 2198-2208.

11 M. Hiyoshi, B. Lee, D. Lu, M. Hara, J. N. Kondo and K. Domen, Catal. Lett., 2004, 98, 181-186.

12 T. Peters, N. Benes, A. Holmen and J. Keurentjes, Appl. Catal., A, 2006, 297, 182-188.

13 S. R. Kirumakki, N. Nagaraju and S. Narayanan, Appl. Catal., A, 2004, 273, 1-9.

14 Y. Yue, H. Liu, Y. Zhou, Z. Bai and X. Bao, Appl. Clay Sci., 2016, 126, 1-6.

15 K. Y. Nandiwale, S. E. Patil and V. V. Bokade, Energy Technol., 2014, 2, 446-452.

16 A. N. Parvulescu, D. Mores, E. Stavitski, C. M. Teodorescu, P. C. Bruijnincx, R. J. K. Gebbink and B. M. Weckhuysen, J. Am. Chem. Soc., 2010, 132, 10429-10439.

17 A. Shahid, S. Lopez-Orozco, V. R. Marthala, M. Hartmann and W. Schwieger, Microporous Mesoporous Mater., 2017, 237, 151-159.

18 G. Xiong, Q. Jia, Y. Cao, L. Liu and Z. Guo, RSC Adv., 2017, 7, 24046-24054.

19 P. Parikh, N. Subrahmanyam, Y. Bhat and A. Halgeri, J. Mol. Catal., 1994, 88, 85-92.

20 G. Bai, J. Han, H. Zhang, C. Liu, X. Lan, F. Tian, Z. Zhao and H. Jin, $R S C A d v ., 2014$, 4, 27116-27121.

21 N. Venkatesha, Y. Bhat and B. J. Prakash, RSC Adv., 2016, 6, 18824-18833.

22 C. D. Chang, C. T. Chu, J. N. Miale, R. F. Bridger and R. B. Calvert, J. Am. Chem. Soc., 1984, 106, 8143-8146.

23 D. Liu, S. Bao and Q. Xu, Zeolites, 1997, 18, 162-170.

24 G. Lietz, K. Schnabel, C. Peuker, T. Gross, W. Storek and J. Volter, J. Catal., 1994, 148, 562-568.

25 Z. Xie, J. Bao, Y. Yang, Q. Chen and C. Zhang, J. Catal., 2002, 205, 58-66.

26 A. Omegna, M. Vasic, J. Anton van Bokhoven, G. Pirngruber and R. Prins, Phys. Chem. Chem. Phys., 2004, 6, 447.
27 Y. Fan, X. Bao, X. Lin, G. Shi and H. Liu, J. Phys. Chem. B, 2006, 110, 15411-15416.

28 Z. Xie, Q. Chen, C. Zhang, J. Bao and Y. Cao, J. Phys. Chem. B, 2000, 104, 2853-2859.

29 S. H. Hansen and S. Pedersen-Bjergaard, 5. Quantitative and Qualitative Chromatographic Analysis, John Wiley \& Sons, 2015.

30 C. J. Van Oers, W. J. J. Stevens, E. Bruijn, M. Mertens, O. I. Lebedev, G. Van Tendeloo, V. Meynen and P. Cool, Microporous Mesoporous Mater., 2009, 120, 29-34.

31 C. Yang and Q. Xuaf, Zeolites, 1997, 19, 404-410.

32 K. Tarach, K. Góra-Marek, J. Tekla, K. Brylewska, J. Datka, K. Mlekodaj, W. Makowski, M. C. Igualada López, J. Martínez Triguero and F. Rey, J. Catal., 2014, 312, 4657.

33 Y. Fan, X. Lin, G. Shi, H. Liu and X. Bao, Microporous Mesoporous Mater., 2007, 98, 174-181.

34 Y. Wang, Y. Sun, C. Lancelot, C. Lamonier, J.-C. Morin, B. Revel, L. Delevoye and A. Rives, Microporous Mesoporous Mater., 2015, 206, 42-51.

35 R. Baran, Y. Millot, T. Onfroy, J.-M. Krafft and S. Dzwigaj, Microporous Mesoporous Mater., 2012, 163, 122-130.

36 J. A. v. Bokhoven, D. C. Koningsberger, P. Kunkeler, H. v. Bekkum and A. P. M. Kentgens, J. Am. Chem. Soc., 2000, 122, 12842-12847.

37 A. Omegna, J. A. van Bokhoven and R. Prins, J. Phys. Chem. B, 2003, 107, 8854-8860.

38 B. Wouters, T.-H. Chen and P. Grobet, J. Am. Chem. Soc., 1998, 120, 11419-11425.

39 A. E. W. Beers, J. A. v. Bokhoven, K. M. d. Lathouder, F. Kapteijn and J. A. Moulijn, J. Catal., 2003, 218, 239-248.

40 M. M. Reddy, M. A. Kumar, P. Swamy, M. Naresh, K. Srujana, L. Satyanarayana, A. Venugopal and N. Narender, Green Chem., 2013, 15, 3474-3483.

41 T.-W. Kim, S.-Y. Kim, J.-C. Kim, Y. Kim, R. Ryoo and C.-U. Kim, Appl. Catal., B, 2016, 185, 100-109.

42 S. Mintova, V. Valtchev, T. Onfroy, C. Marichal, H. Knözinger and T. Bein, Microporous Mesoporous Mater., 2006, 90, 237245.

43 T. Ikuno, W. Chaikittisilp, Z. Liu, T. Iida, Y. Yanaba, T. Yoshikawa, S. Kohara, T. Wakihara and T. Okubo, J. Am. Chem. Soc., 2015, 137, 14533-14544.

44 F. Tian, Y. Wu, Q. Shen, X. Li, Y. Chen and C. Meng, Microporous Mesoporous Mater., 2013, 173, 129-138.

45 S. Dzwigaj, Y. Millot, C. Méthivier and M. Che, Microporous Mesoporous Mater., 2010, 130, 162-166.

46 J. Janas, J. Gurgul, R. P. Socha, T. Shishido, M. Che and S. Dzwigaj, Appl. Catal., B, 2009, 91, 113-122.

47 C. A. Emeis, J. Catal., 1993, 141, 347-354.

48 M. Maache, A. Janin, J. Lavalley, J. Joly and E. Benazzi, Zeolites, 1993, 13, 419-426.

49 M. R. Apelian, A. S. Fung, G. J. Kennedy and T. F. Degnan, J. Phys. Chem., 1996, 100, 16577-16583.

50 J. W. Ward, J. Catal., 1967, 9, 225-236.

51 M. Guisnet, P. Ayrault and J. Datka, Microporous Mesoporous Mater., 1998, 20, 283-291. 
52 B. Sulikowski, J. Datka, B. Gil, J. Ptaszynski and J. Klinowski, J. Phys. Chem. B, 1997, 101, 6929-6932.

53 B. M. Chandra Shekara, B. S. Jai Prakash and Y. S. Bhat, ACS Catal., 2011, 1, 193-199.
54 J. Higgins, R. B. LaPierre, J. Schlenker, A. Rohrman, J. Wood, G. Kerr and W. Rohrbaugh, Zeolites, 1988, 8, 446-452.

55 J. Zhao, H. Guan, W. Shi, M. Cheng, X. Wang and S. Li, Catal. Commun., 2012, 20, 103-106. 